\title{
A Study on the Effectiveness of Podcasting in Higher Education
}

\author{
Aleksandr Volodin \\ Moscow Region State University \\ Moscow, Russia \\ E-mail: voalan@ rambler.ru
}

\author{
Andrei Volodin \\ Moscow Institute of Humanities \\ Moscow, Russia \\ E-mail: volodinand@mail.ru
}

\begin{abstract}
The paper reports on empirical findings on the effectiveness of the podcasting application method in teaching university students. It considers stages and levels of the experiment as well as its conditions and sampling. The sample consists of students enrolled in the program of higher professional education 54.03.01 "Design". For evaluation of the students' learning outcomes the authors employ tests, interviews and practical assignments. The data collected during the experiment are processed and analyzed with help of Student's t-test and Spearman's rank correlation method.
\end{abstract} teaching

Keywords-podcasting; experiment; performance evaluation;

\section{INTRODUCTION}

IT penetration is one of the main factors that determines the evolution dynamics of modern society. The role of information technologies in the development of human abilities cannot be overestimated. In the conditions of the information society, an IT environment of educational organizations is strongly sought after. It is well known that an IT environment has a specific integrative nature and serves as a space for professional and personal growth in the course of training. However, it is essential that, when pursuing opportunities, students have such training in their career path that corresponds to the demands set by the information society. In this connection, the introduction of innovative information and communication technologies that possess boundless didactic opportunities is seen as one of the methods of improving students' quality and performance at university.

Today the Internet is rich in technologies and services such as thematic forums, blogs, twitter, wiki, social bookmarking, YouTube, IP-and Voice over IP (Skype, ooVoo, AOL Instant Messenger, Brosix, Ekiga, KPhone, Linphone, Mercuro IMS Client), Google circles, social networks groups, Instagram, RSS, podcasting and many others. In spite of the rapid development of Russian modern information space, growth of computer technologies in economy and education, and increasing numbers of computer users caused by the Internet boom, we can admit that using modern IT in higher education at present is lacking. Bridging this gap is a burning issue for pedagogical theory and practice including within the sphere of Russian higher education.
All in all, fast-growing information technologies and internet services form the rationale of IT development in the sphere of higher education. Nowadays there is a demand for innovative pedagogical technologies, in which new teaching forms and methods, along with the teaching process organization, are implemented on the basis of network computer systems.

One of the fastest-developing IT technologies in the world information space is podcasting.

The theoretical research conducted by the authors revealed general and essential characteristics of the notions, and defines them as follows:

- Podcasting is a set of methods, operation, software and hardware tools in creating, publishing and distributing content via the Internet in various formats (audio- and video files, digital documents and/or their combinations) to subscribers' electronic devices using RSS or Atom.

- A Podcast is content created, published and distributed via the Internet in various forms (audioand video files, digital documents and/or their combinations) to subscribers' electronic devices [18].

At present, using podcasting in teaching students at higher educational establishments has to be based on pedagogically tested approaches and teaching methods. We have positive experience when using podcasting and podcasts in teaching, as demonstrated by the following research:

- $\quad$ students' motivation for using podcasts [9, 11];

- students' independent work when using podcasts as a research activity $[10,14,17]$;

- factors encouraging students to use podcasting [6];

- the influence of podcasts on teaching and learning process [13];

- the influence of screencasts on teaching and learning process [8];

- using podcasts as an alternative to lectures [12]; 
- the influence of podcasts on medical students' learning outcomes [15];

- students' preferences in the social media and their influence on student-university interaction [7];

- teacher training based on multimedia technologies [5].

In accordance with the suggested and tested hypothesis of the research, if podcasting and podcasts of different types are employed in the teaching process at university, it will improve students' level of training.

\section{ORGANISATION OF EMPIRICAL OBSERVATION}

For testing, the suggested hypothesis we practically tested and endorsed methodological approaches to integration and using podcasting and podcasts in the teaching and learning process at Moscow Institute of Humanities. The approbation was carried out in the course of the pedagogical experiment aimed at the performance evaluation of the worked out methodological approaches [18]. The assessment tool for performance evaluation when using podcasting in the teaching and learning process is the level of the students' learning outcomes.

The conducted experiment included three stages: ascertaining experiment, formative experiment and analytical experiment. At the ascertaining stage of the pedagogical experiment we set the following tasks: formation of the student body (check sample and experimental sample), assessment methods selection and statistical processing of the results.

The experimental groups were formed of those students who had given their consent to participate in the preparatory training with the use of the podcasting technology. They also had to meet the following criteria:

- active use of the smartphone, tablet computer or notebook with high-speed Internet access (3G, LTE or a dedicated link);

- considerable experience in working with electronic devices;

- experience in using multimedia content and podcasts including educational podcasts. Such requirements were not imposed on the students from the control groups.

The experimental groups were taught some of the disciplines of the curriculum with the use of podcasting. The control groups were taught the same disciplines without the podcasting method. We filtered 6 samples ( 3 of the control groups and 3 of the experimental groups). The sample consisted of 91 students, all of which are enrolled in the program of higher professional education 54.03.01 "Design" "Table I".
TABLE I. EXPERIMENT PARAMETERS

\begin{tabular}{|l|l|l|l|l|l|l|}
\hline № & Discipline & ECTS & Year & \multicolumn{2}{|c|}{ Sample size } & $\begin{array}{c}\text { Evaluation } \\
\text { tool }\end{array}$ \\
\hline & & & & control & $\begin{array}{c}\text { experi } \\
\text { mental }\end{array}$ & \\
\hline 1 & History & 3 & 1 & 15 & 14 & Test \\
\hline 2 & $\begin{array}{l}\text { Philosoph } \\
\text { y }\end{array}$ & 4 & & & & Test \\
\hline 3 & $\begin{array}{l}\text { Academic } \\
\text { drawing }\end{array}$ & 12 & 3 & 16 & 14 & $\begin{array}{l}\text { Practical } \\
\text { assignment }\end{array}$ \\
\hline 4 & $\begin{array}{l}\text { Academic } \\
\text { painting }\end{array}$ & 12 & & & & $\begin{array}{l}\text { Practical } \\
\text { assignment }\end{array}$ \\
\hline 5 & Design & 20 & 4 & 14 & 18 & $\begin{array}{l}\text { Practical } \\
\text { assignment }\end{array}$ \\
\hline
\end{tabular}

The validity of the sample comparison (the experimental and control groups) according to the criteria was conditioned by the fact that all the groups had the same curriculum classes; the time allocated for each discipline was identical; classes were organized in the same conditions and with identical evaluation tools for grading students. The fact that no preparatory training in the disciplines was conducted was taken into account as well. Therefore, we may assume the equality of the samples (student groups) under consideration [1]. The difference lay in using podcasting as a teaching medium in the course of student training in the experimental groups. This training was based on the developed methodological approaches. In the control groups no podcasting was applied.

We evaluated performance of the methodological approaches to using podcasting in training with help of the following evaluation tools developed at university for successful implementation of higher education programme 54.03.01 "Design":

- reports and essays;

- test banks for the disciplines (computer-based testing);

- test questions and tasks for grading in the disciplines;

- installations and exhibitions in the course of which we assess students' practical assignments. All evaluation tools were developed by the academic teaching staff in charge of higher education program 54.03.01 "Design".

We took two approaches for assessment of the learning outcomes. The first-year students' grading in history and philosophy consisted of computer testing based on the test banks. As for the third - and fourth-year students, we graded academic drawing, academic painting and design by analyzing the students' practical assignments. The data collected during the grading process were pre-processed and served as a basis for analyzing and comparing the results of the pedagogical experiment at the control stage.

Based on the results of computer testing in history and philosophy, we calculated their values of statistical validity using the Student's t-criterion. The test banks were developed according to the principles described in the researches $[2,3$, $4,16]$. These test banks, or criterion-oriented tests, had high content validity (from 0.83 to 0.93 - scientific assessment) 
and high reliability (from 0.91 to 0.94 defined by the method of dividing the test into two at a single-step testing. The instrument used for testing and processing the results was the software tool "Adaptive Test Environment , or ACT".

The students' results in academic drawing, academic painting and design were rated on a five-grade scale. For analyzing the grades based on a five-grade scale, we calculated a reliability coefficient for each discipline according to Spearman's Rank-Order Correlation. This method makes it possible to define the strength and direction of the correlation relationship between the two attributes ranking, i.e. grades of the control and experimental groups. For calculating rank-order correlation it is essential to have two rows of values that can be rated. In our case such rows are represented by the two groups of attributes ranking (groups of grades in each discipline of the control and experimental groups).

\section{THE FORMING EXPERIMENT}

At the forming stage of the pedagogical experiment we taught the students and graded their work. Taking into account the suggested hypothesis, we devised and tested two methodological approaches to integrating podcasting into student training. The methodological approaches were applied depending on the forms of the lesson organization according to the higher educational program 54.03.01 "Design". The first methodological approach dealt with the use of podcasting at lectures, the second one did the same in practical classes.

It is typical of the first methodological approach to use podcasting immediately after the lecture. In this case a podcast contains the main conclusions and resume of the lecture as well as answers to questions in the course of the lecture, extra material and/or assignments for independent work. So, podcasts act as additions to the traditional means of education (e.g., using notes made during the lecture, using textbooks and learning material). After testing the first methodological approach we came to the conclusion that it was efficient to make video podcasts as education podcasts from 15 to 30 minutes long.

In accordance with the second methodological approach, podcasting is used both before and after a practical class. In the first case, the educational podcast contains general information on practical assignments, recommendations on preparation for classes and some other information of an organizational nature. In the second case, an educational podcast encompasses the main conclusions and an outline of a practical assignment, sample techniques and approaches to doing tasks, answers to questions, additional material and assignments for independent work. In this situation educational podcasts serve as supplementary material to traditional means of education (e.g., using notes made during practical classes, working with a textbook or other learning materials). In the course of testing the second methodological approach we came to the conclusion that it was efficient to make video podcasts as education podcasts from 15 to 30 minutes long or as slidecasts, if necessary.
In the course of testing both methodological approaches we found that video podcasts from 45 to 90 minutes long could contain the material of the whole class (a lecture or a practical class), which gave absent students an opportunity to be familiar with its content. Video podcasts are of particular importance to practical classes due to the specific character of teaching design students, which reveals itself in the vivid visual demonstration of practical methods, ways and techniques of designing objects of art (design projects) of different forms. Besides, podcasts are used as reference material for preparing students for grading.

By now there has been created and posted a great number of podcasts from different spheres of human activity, including education. Today it is becoming of vital importance not only to create podcasting and podcasts but also to be able to employ posted podcasts and make a good selection of them to be used in the teaching process.

For testing the methodological approaches the teaching staff selected podcasts which were in compliance with the curriculum and were actively used in training students. Thus, a whole set of podcasting was obtained according to the curriculum. The language of all podcasting was Russian.

For the discipline "Academic painting":

- the official channel of artist Igor Sakharov. The author presents podcasting dedicated to methods of painting a portrait, still life and a landscape. He also gives information on working with painting materials and equipment.

- the official channel of artist sergei gusev. the author presents podcasting dedicated to methods of painting a portrait, figure, still life and a landscape. He pays attention not only to the Old Masters' techniques but also to modern methods of artistic execution of paintings.

For the discipline "Academic Drawing":

- the official channel ArtStudying. The podcasting contains a series of videos dedicated to working on various installations of academic painting. Much attention is paid to techniques of positioning the depicted objects, composition, painting techniques and plastic anatomy from the very beginning.

For the discipline "Design":

- metrika. This podcasting is about technologies and designing interfaces and services. It may be of interest to designers of web resources: web sites, blogs and other projects on different internet platforms.

- design guru. This podcasting focuses on design and programming. It may be of interest to layout artists, designers of web resources and those involved in publishing activities. A wide range of questions about design are discussed. 


\section{DISCUSSION}

At the analytical stage of the pedagogical experiment we used statistical analysis and interpreted the students' grading results.

We present the statistic processing and interpretation results of the students' grading using Student's t-criterion and formulate the null $\left(\mathrm{H}_{0}\right)$ and alternative $\left(\mathrm{H}_{1}\right)$ hypotheses of the statistical check: $\mathrm{H}_{0}$, the average level of the learning outcomes in history (philosophy) in the control and experimental groups, is statistically similar. $\mathrm{H}_{1}$, the average level of the learning outcomes in history (philosophy) in the control and experimental groups, is statistically dissimilar.

According to the calculation methodology [1. P. 139-154], we adopt $\mathrm{p}$-level $5 \%(\mathrm{p}=5 \%)$, i.e. we adopt the risk of error in the output in five out of one hundred cases at test-takers' random sampling for each experiment.

Now we are in a position to compare t-values obtained during the experiment with the tabulated value of student's distribution taking into account the degrees of freedom which equal the number of test-takers in both groups (samplings) minus two. If the t-value obtained during the experiment is greater than the tabulated value at the selected significance level and degrees of freedom, then there is reason for accepting the experimental hypothesis. Comparing the tabulated t-value with the calculated t-value of Student's distribution, we can make a conclusion about the statistical validity of the difference in the students' learning outcomes in the experimental and control groups.

Based on the results of the students' tests from the experimental and control groups, we made an automated calculation of the student's t-distribution. In history the calculated $\mathrm{t}=6.6$; in philosophy $\mathrm{t}=3.6$ "Table II".

TABLE II. The CALCUlation RESUlts of Statis TiCAL VAluE of STUDENT'S T-DISTRIBUTION

\begin{tabular}{|l|l|l|l|c|}
\hline \multicolumn{1}{|c|}{ Discipline } & \multicolumn{2}{c|}{ History } & \multicolumn{2}{c|}{ Philosophy } \\
\hline Critical value t & $\mathrm{p} \leq 0.05$ & $\mathrm{p} \leq 0.01$ & $\mathrm{p} \leq 0.05$ & $\mathrm{p} \leq 0.01$ \\
\hline & 2.05 & 2.77 & 2.05 & 2.77 \\
\hline Empirical value t & 6.6 & 3.6 & \\
\hline
\end{tabular}

The differences discovered between the control and experimental samples are significant, being more than at the five-percent level, i.e. the average level of the students' learning outcomes in history and philosophy in the experimental group is higher than that in the control group. In terms of statistic hypotheses this statement reads as follows: hypothesis $\mathrm{H}_{0}$ on identity is rejected, and at the $5 \%$ level an alternative hypothesis $\mathrm{H}_{1}$ on the difference between the experimental and control groups is accepted.

We next describe the statistical processing and interpretation of the students' grading results with help of Spearman's rank correlation method. We formulate the null $\left(\mathrm{H}_{0}\right)$ and alternative $\left(\mathrm{H}_{1}\right)$ hypotheses of the statistic check as follows: $\mathrm{H}_{0}-$ profiles of the students' grades in the disciplines (academic drawing, academic painting, design) in the control and experimental samples are not statistically correlated. $\mathrm{H}_{1}-$ profiles of the students' grades in the disciplines (academic drawing, academic painting, design) in the control and experimental samples are statistically correlated.

Based on the results of the students' tests from the experimental and control groups, we made an automatic calculation of values using Spearman's method of rank correlation and obtained the following results "Table III"

TABLE III. VAlue CALCUlation Results Based on SPEARMan's RANK CORRELATION

\begin{tabular}{|l|l|l|l|l|l|c|}
\hline $\begin{array}{c}\text { Disciplin } \\
\text { e }\end{array}$ & \multicolumn{2}{|c|}{$\begin{array}{c}\text { Academic } \\
\text { drawing }\end{array}$} & \multicolumn{2}{c|}{$\begin{array}{c}\text { Acade mic } \\
\text { painting }\end{array}$} & \multicolumn{2}{c|}{ Design } \\
\hline $\begin{array}{l}\text { Critical } \\
\text { values rs }\end{array}$ & $\mathrm{p} \leq 0.05$ & $\mathrm{p} \leq 0.01$ & $\mathrm{p} \leq 0.05$ & $\mathrm{p} \leq 0.01$ & $\mathrm{p} \leq 0.05$ & $\mathrm{p} \leq 0.01$ \\
\hline & 0.5 & 0.64 & 0.5 & 0.64 & 0.47 & 0.6 \\
\hline $\begin{array}{l}\text { Empirical } \\
\text { values rs }\end{array}$ & -0.04 & -0.164 & -0.382 & \\
\hline
\end{tabular}

As it is seen from Table 3 , we accept the hypothesis $\mathrm{H}_{0}$ for the discipline "Academic drawing". The correlation between the groups does not reach the level of statistical significance. The absence of correlation means that the results of the control and experimental groups are statistically dissimilar. In this case we compare their mean values. Here the mean, the larger number in absolute value, shows the prevailing level of the students' academic progress. For academic drawing the mean in the control and experimental groups is the following: in the control group: 3.75 scores; in the experimental: 4.5 scores, which attests a higher level of academic progress in the experimental group compared with the control one.

For the discipline "Academic painting", it follows from Table 3 that the hypothesis $\mathrm{H}_{0}$ is accepted. The correlation between the groups does not reach the level of statistical significance. The absence of correlation means that the results of the control and experimental groups are statistically dissimilar. In this case we compare their mean values. Here the mean, the larger number in absolute value, shows the prevailing level of the students' academic progress. For academic painting the mean in the control and experimental groups is the following: 3.94; in the experimental: 4.57 , which attests a higher level of academic progress in the experimental group compared with the control

For the discipline "Design", it follows from Table 3 that hypothesis $\mathrm{H}_{0}$ is accepted. The correlation between the groups does not reach the level of statistical significance. The absence of correlation means that the results of the control and experimental groups are statistically dissimilar. In this case we compare their mean values. Here the mean, the larger number in absolute value, shows the prevailing level of the students' academic progress. For design the mean score in the control and experimental groups is the following: 3.79 scores; in the experimental: 4.39 scores, which attests a 
higher level of academic progress in the experimental group compared with the control one.

\section{CONCLUSION}

In regards to the above, we affirm that the suggested hypothesis is justified. The statistical analysis of the students' grading results demonstrates that the learning outcomes in the experimental group are significantly better than in the control group. Thus, we make the conclusion that teaching students using podcasting and podcasts promotes learning these disciplines more effectively.

\section{RECOMMENDATIONS}

The results of the research provide a theoretical and methodical basis for solving urgent theoretical and practical problems of using innovative ICT in education. The results of the research develop theoretical fundamentals for creating and using new pedagogical technologies and methodical systems of education based on ICT. They also contribute to theory, teaching methods and practice of IT development in education, and demonstrate in practice how using ICT in higher education can be employed. Besides, they expand the opportunities of improving students' academic activity and facilitate the training of modern professionals.

Further research in the field can be carried out in accordance with the immediate prospects of developing requirements to educational content, ICT performance evaluation in the system of secondary, secondary vocational, higher and further education, providing organizational and pedagogical grounds for introducing and improving ICT in education.

\section{REFERENCES}

[1] Avanesov V.S. Application of statistical methods and computers in educational research // Introduction to the scientific study of pedagogy. Moscow: Education, 1988. P. 139-154.

[2] Avanesov V.S. Theoretical Foundations of development tasks in the test form. Moscow: Higher School, 1995. 56 p.

[3] Chelyshkova M.B. Theory and practice of designing of pedagogical tests. Moscow: Logos, 2002. 432 p.

[4] Chelyshkova, M.B., Savelyev B.A. Guidelines for the development of tests for a comprehensive fitness of students in high school. Moscow: Higher School, 1995. 41 p.

[5] Ely, E (Ely, Emily); Kennedy, MJ (Kennedy, Michael J.); Pullen, PC (Pullen, Paige C.); Williams, MC (Williams, Mira Cole); Hirsch, SE (Hirsch, Shanna Eisner). Improving instruction of future teachers: A multimedia approach that supports implementation of evidence-based vocabulary practices // TEACHING AND TEACHER EDUCATION. NOV 2014. Vol. 44. P. 35-43. DOI: 10.1016/j.tate.2014.07.012

[6] Merhi, MI (Merhi, Mohammad I.). Factors influencing higher education students to adopt podcast: An empirical study // COMPUTERS \& EDUCATION. APR 2015. Vol. 83. P. 32-43. DOI: 10.1016/j.compedu.2014.12.014

[7] Meyliana (Meyliana); Hidayanto, AN (Hidayanto, Achmad Nizar); Budiardjo, EK (Budiardjo, Eko Kuswardono). Evaluation of Social Media Channel Preference for Student Engagement Improvement in Universities Using Entropy and Topsis Method // JOURNAL OF INDUSTRIAL ENGINEERING AND MANAGEMENT-JIEM. 2015. Vol. 8. Rel. 5. P. 1676-1697. DOI: 10.3926/jiem. 1652
[8] Morris, C (Morris, Cecile); Chikwa, G (Chikwa, Gladson). Screencasts: How effective are they and how do students engage with them? // ACTIVE LEARNING IN HIGHER EDUCATION. MAR 2014. Vol. 15. Rel. 1. P. 25-37. DOI: 10.1177/1469787413514654

[9] Moss, ND (Moss, Nathan D.); Hamilton, K (Hamilton, Kyra); White, KM (White, Katherine M.); Hansen, J (Hansen, Julie). The changing motivations of students' use of lecture podcasts across a semester: an extended theory of planned behaviour approach // INNOVATIONS IN EDUCATION AND TEACHING INTERNATIONAL. NOV 2. 2015. Vol. 52. Rel. 6. P. 599-609. DOI: 10.1080/14703297.2012.746513

[10] Muller, C (Mueller, Christian). Podcasting in higher education challenging but fun and great for learning // EDULEARN12: 4TH INTERNATIONAL CONFERENCE ON EDUCATION AND NEW LEARNING TECHNOLOGIES. 4th International Conference on Education and New Learning Technologies (EDULEARN). 2012. P. 1720-1725.

[11] Nozari, Ali Yazdanpanah; Siamian, Hasan. The effect of applying podcast multimedia teaching system on motivational achievement and learning among the boy students // Acta informatica medica : AIM : journal of the Society for Medical Informatics of Bosnia \& Herzegovina : casopis Drustva za medicinsku informatiku BiH. 2015Feb (Epub 2015 Feb 22). Vol. 23. Rel. 1. P. 29-32. DOI: 10.5455/aim.2015.23.29-32

[12] O'Bannon, BW (O'Bannon, Blanche W.); Lubke, JK (Lubke, Jennifer K.); Beard, JL (Beard, Jeffrey L.); Britt, VG (Britt, Virginia G.). Using podcasts to replace lecture: Effects on student achievement // COMPUTERS \& EDUCATION. NOV 2011. Vol. 57. Rel. 3. P. 18851892. DOI: 10.1016/j.compedu.2011.04.001

[13] Pi, ZL (Pi, Zhongling); Hong, JZ (Hong, Jianzhong). Learning process and learning outcomes of video podcasts including the instructor and PPT slides: a Chinese case // INNOVATIONS IN EDUCATION AND TEACHING INTERNATIONAL. MAR 3, 2016. Vol. 53. Rel. 2. P. 135-144. DOI: 10.1080/14703297.2015.1060133

[14] Powell, L (Powell, Lynne); Robson, F (Robson, Fiona). Learnergenerated podcasts: a useful approach to assessment? // INNOVATIONS IN EDUCATION AND TEACHING INTERNATIONAL. MAY 4. 2014. Vol. 51. Rel. 3. P. 326-337. DOI: 10.1080/14703297.2013.796710

[15] Raupach, T (Raupach, Tobias); Grefe, C (Grefe, Clemens); Brown, J (Brown, Jamie); Meyer, K (Meyer, Katharina); Schuelper, N (Schuelper, Nikolai); Anders, S (Anders, Sven). Moving Knowledge Acquisition From the Lecture Hall to the Student Home: A Prospective Intervention Study // JOURNAL OF MEDICAL INTERNET RESEARCH. SEP 2015. Vol. 17. Rel. 9. DOI: 10.2196/jmir.3814

[16] Vasilyev V.I., Tyagunova T.N. Basics culture adaptive testing. Moscow: Icarus, 2003. 584 p.

[17] Vasquez, VM (Vasquez, Vivian Maria). Podcasting as Transformative Work // THEORY INTO PRACTICE. APR 3. 2015. Vol. 54. Rel. 2. SI. P. 147-153. DOI: 10.1080/00405841.2015.1010848

[18] Volodin A.A., Volodin A.A. Metodika use of podcasting technology in teaching: Monograph. Podolsk: Mogi, 2013. 98 p. 